conjugates, malonic dialdehyde and the main components of the antioxidant system, (ceruloplasmin, vitamin E) in the liver of animals. The results obtained were subjected to statistical analysis with calculation of parametric criteria Student.

It was found out that in the liver tissue of experimental animals a daily heat exposure during forty-five minutes contributes to the increase of lipid hydroperoxides level (by $34-41 \%$ ), of diene conjugate (by $45-50 \%$ ), and of malonic dialdehyde (by $62-74 \%$ ) against the decrease of antioxidant system activity in the liver of intact animals. The introduction of the phytoadaptogens to rats in the conditions of heat exposure contributes to the reliable decrease in the liver of lipid hydroperoxides by $22-28 \%$, of diene conjugates - by $22-32 \%$, and of malonic dialdehyde by $30-37 \%$ in comparison with the rats of the control group. While analyzing the effect of the phytoadaptogens on the activity of the components of antioxidant system it was shown that the level of ceruloplasmin in the liver of animals was reliably higher by $68-82 \%$, of vitamin E by $42-65 \%$ in comparison with the same parameters of the rats of the control group.

So, the application of the phytoadaptogens in the conditions of long heat exposure of the organism of animals under experiment leads to the stabilization of the processes of peroxidation against the increase of antioxidant system activity.

\title{
REFERENCES
}

Dorovskikh V.A., Borodin E.A., Lee O.N., Simonova N.V., Starberg M.A., Dorovskikh Yu.V. Comparative efficiency of different antioxidants during cold exposure and overheating. Blagoveshchensk; 2016 (in russian).

Dorovskikh V.A., Borodin E.A., Shtarberg M.A., Shtarberg S.A., Egorov K.E. Phospholipids as antiatherosclerotic drugs. In book: Lipoproteins and atherosclerosis. Abstracts of the Symposium devoted to the 110 anniversary from the birthday of academician N.N. Anichkov "Lipoproteins and atherosclerosis». Moscow; 1995: 41-46 (in russian).

Dorovskikh V.A., Tseluyko S.S., Simonova N.V., Anokhina R.A. In the world of antioxidants. Blagoveshchensk, 2012 (in russian). Landyshev Ju.S., Dorovskikh V.A., Tseluyko S.S., Lazutkina E.L., Tkacheva S.I., Chaplenko T.N. Bronchial asthma. Blagoveshchensk, 2010 (in russian).

Landyshev Ju.S., Dorovskikh V.A., Chaplenko T.N. Drug Allergy. St-Petersburg, 2010 (in russian).

Simonov V.A., Simonova N.V. Method of correcting lipid peroxidation in animal white muscle disease. Krasnoyarsk, 2006 (in russian).

Simonova I.V., Dorovskikh V.A., Simonova N.V., Shtarberg M.A. Non-specific preventive measures against respiratory diseases of nursery age children. Far Eastern Medical Journal 2009; 3:56-58 (in russian).

Simonova N.V. Herb extracts and oxidative stress in the ultraviolet irradiation conditions. Agricultural research Journal 2011; 8:23-26 (in russian).

Simonova N.V., Dorovskikh V.A., Anokhina R.A. Medicinal plants of the Amur region. Blagoveshchensk; 2016 (in russian).

Simonova N.V., Dorovskikh V.A., Shtarberg M.A. Effect of adaptogens of plant origin on the intensity of the processes of peroxidation of lipids of membranes under conditions of ultraviolet irradiation. Far Eastern Medical Journal 2010; 2:112-115 (in russian).

Simonova N.V., Dorovskikh V.A., Simonova N.P. Ultraviolet radiation and oxidative stress. The possibility of phitocorrection. Blagoveshchensk, 2014 (in russian).

Simonova N.V., Dorovskikh V.A., Li O.N., Shtarberg M.A., Simonova N.P. Tincture of medicinal plants and oxidative stress in the conditions of cold influence. Bulletin physiology and pathology of respiration 2013; 48:76-80 (in russian).

Simonova N.V., Lachin A.P, Simonova N.P. Efficiency in correction phytopreparations of lipid peroxidation of biomembranes the background ultraviolet radiation. Vestnik Krasnoyarsk state agrarian University 2010; 5:95-98 (in russian).

Zenkov N.K., Kandalintseva N.V., Lankin V.Z., Men'shchikova E.B., Prosenko A.E. Phenolic Bioantioxidant. Novosibirsk: SB RAMS; 2003 (in russian).

\section{DOI 10.22448/AMJ.2017.3.68-69 \\ THE EXPERIMENTAL STUDY ON THE MOLECULAR MECHANISM OF THE EFFECT OF ACUPOTOMY ON CHONDROCYTE OF KNEE OSTEOARTHRITIS}

\section{SONG Han-bing}

Heilongjiang University of Chinese Medicine, Heping Road 24, Harbin 150040, China. Email: 106855941@qq.com

Abstract Osteoarthritis of the knee is a kind of arthritis, mainly in the knee joint, knee joint surface abnormal structure change as the main case, such as bone hyperplasia, bone wear, bone degeneration, etc.. [1] The final development of arthritis disease. This experiment adopts the Acupotomy operation model for treatment of knee osteoarthritis in rabbits, through observation of the response to treatment and a variety of rabbit knee osteoarthritis (KOA) changes of related molecules, evaluation of acupotomy operation treatment, the mechanism of acupuncture therapy and the corresponding inquiry theory. To provide new ideas and theoretical data for the treatment of acupotomy. In this study, KOA model was made by papain injection. The severity of knee injury was assessed using the knee osteoarthritis severity index. Acupotomy group method of operation, the first is in the bone around the knee joint of rabbit arthritis model for pain response, by touching the way of looking for rabbits reaction around the joint pain sensitive and cord like nodules, 5 points as Acupotomy starting point, using Acupotomology and manipulation of releasing and needle knife technique the horizontal and vertical two ways, in which the horizontal to release, to clear the main direction. The effect of acupotomy in the treatment of knee osteoarthritis is obvious, and its mechanism may be related to IL-1, TNF-a, MMP-3 and other cartilage cells. 
Knee osteoarthritis is a degenerative and long-term injury lesions, the primary population is mainly concentrated in the elderly and long-term knee injuries of knee osteoarthritis in the crowd, often slow onset, obese women are more common, knee joint activities, weight-bearing pain significantly increased pain in the beginning is often the latter is paroxysmal, persistent pain, pain when walking on the stairs, down the stairs is particularly evident, even when walking claudication. Severe may also appear in the joints of the body and muscle disorders and inflammatory effusion.[2] It is characterized by joint swelling and pain, active friction, flexion and extension, and other activities, and chronic inflammation can lead to abnormal changes of joints. The articular cartilage degeneration is very obvious, the common cartilage degeneration and destruction is the main pathological features of the disease. [3]

At present, KOA has been used in the treatment of KOA, but the mechanism of acupotomy lysis is only limited to the macro level of biomechanics. However, in the observation of many clinical cases in the Acupotomy articular cartilage patients with KOA have been repaired in different degrees, so the treatment mechanism needs further discovery and in-depth research, this study is through the animal experiment to evaluate the acupotomy therapy on the solution of KOA in chondrocytes the molecular mechanism of action, in order to observe the Acupotomy operation of Knee Osteoarthritis Chondrocytes molecular mechanism, in order to analyze the pathological basis of acupuncture therapy in the treatment of knee osteoarthritis, clinical effect for validation of modern medicine theory foundation.

Objective This experiment adopts the Acupotomy operation model for treatment of knee osteoarthritis in rabbits, through observation oftheresponsetotreatmentandavariety ofrabbitkneeosteoarthritis(KOA)changes ofrelated molecules, evaluation of acupotomy operation treatment, the mechanism of acupuncture therapy and the corresponding inquiry theory.

Materials and methods The rabbits were randomly divided into 2 groups, each of which consisted of 2 rabbits and two male rabbits. There were 4 groups, and 32 rabbits were involved in the experiment. A model of osteoarthritis of the knee joint was selected in healthy rabbits. The methods of intervention were acupotomy and electroacupuncture.

Results and discussion This experiment adopts the Acupotomy operation in the treatment of rat model of KOA was studied, and the possible mechanism of acupotomy therapy are discussed in detail, proved that acupotomy therapy can regulate the IL-1, TNF-a, and the abnormal expression of MMPs-3, resulting in the therapeutic effect, early step explains the mechanism of acupotomy cell molecular level for patients the treatment of KOA, and provide experimental evidence for clinical application and reliable treatment.

\title{
References:
}

[1] Ji Bo, Guo Changqing, Jin Yan, et al. Effects of acupuncture and acupuncture on knee osteoarthritis pain threshold in rats and central monoamine neurotransmitters in [J]. Chinese pathophysiol, 2010,26 (6): 1091-1095.

[2] Zhang Xianjie, Wang Changxing, et al. Research progress on the relationship between traditional Chinese medicine treatment of osteoarthritis and matrix metalloproteinases [J]. Journal of Orthopaedics and traumatology of Chinese medicine, 2015,23 (1): 65-68.

[3] Ahsin S, Saleem S, Bhatti AM, et al. Clinical and endocrinologicalchanges after electro-acupuncture treatment in patients withosteoarthritis of the knee [J]. Pain, 2009,147(1): 60-66.

\section{DOI 10.22448/AMJ.2017.3.69-70 STUDY ON HPLC FINGERPRINT OF TROLLIUS LEDEBOURII REICHB.}

\author{
SU Lianjie, YU Ruifeng
}

( Heilongjiang University of Traditional Chinese Medicine, Harbin 150040, China)

\section{ZHAO Jinchuan}

(Georg-August-University Goettingen,Goettingen 37075,Germany)

Abstract Objective: To evaluate quality of medical materials by similarity calculation, establishing fingerprint characteristics analysis of Trollius ledebourii Reichb based on reversed phase high performance liquid chromatography (HPLC).

Methods: Referring to orientin, to analysis Trollius ledebourii Reichb from 12 different habitats by HPLC gradient elution, and process similarity calculation and system cluster analysis. Chromatographic conditions: Welch Materials Ultimate TMXB-C18(250 $\mathrm{mm} \times 4.6 \mathrm{~mm}, 5 \mu \mathrm{m})$ chromatographic column, mobile phase of acetonitrile- $0.16 \%$ phosphoric acid, $340 \mathrm{~nm}$ detection wavelength, $1.0 \mathrm{ml} / \mathrm{min}$ flow rate, $30^{\circ} \mathrm{C}$ column temperature .

Results: This study established HPLC fingerprint characteristics analysis of Trollius ledebourii Reichb, marked 17 common peak, and analysis methodology to investigate the results conformed to the requirements of fingerprint technology; Similarity and cluster analysis show that the quality of Trollius ledebourii Reichb is mainly related to its source.

Conclusion: This research method is reliable, reproducible and can be used for scientific evaluation and quality monitoring in medical material of Trollius ledebourii Reichb.

Key words: Trollius ledebourii Reichb ; HPLC ; Fingerprint; Orientin; Similarity; Cluster analysis 